\title{
FROM MIDI TO MALAY-MUSLIM-FRIENDLY: HOSPITAL UNIVERSITI SAINS MALAYSIA'S JOURNEY IN MALAYSIANISING ITS NURSING UNIFORM
}

\section{Salilah Saidun ${ }^{1,2^{*}}$ and Elmira Akhmetova ${ }^{1}$}

${ }^{1}$ Department of History and Civilization, Kuliyyah of Islamic Revealed Knowledge and Human Sciences, International Islamic University Malaysia, Kuala Lumpur, MALAYSIA

${ }^{2}$ Department of Islamic Sciences, College of Education, Sultan Qaboos University, Muscat 123, OMAN

*Corresponding author: s_salilah@yahoo.com

Published online: 30 October 2020

To cite this article: Salilah Saidun and Elmira Akhmetova. 2020. From midi to Malay-Muslimfriendly: Hospital Universiti Sains Malaysia's journey in Malaysianising its nursing uniform. Kajian Malaysia 38(2): 1-24. https://doi.org/10.21315/km2020.38.2.1

To link to this article: https://oi.org/10.21315/km2020.38.2.1

\begin{abstract}
Nursing uniforms have undergone various metamorphoses since Malaysia gained independence. This article presents the process of transforming the nursing uniform at the Hospital Universiti Sains Malaysia (HUSM) between 1983 and 2017. In this historical case study, content analysis was conducted on the data obtained through library research and face-to-face interviews. The HUSM nursing uniform evolution can be categorised into three phases: the inauguration of the unique HUSM image and the negotiation for Malay-Muslim-friendly nursing uniforms (from 1983 to the mid-1990s); the officiation of the Malay-Muslimfriendly nursing uniform (from the mid-1990s to 2011); and the enhancement of the HUSM image (from 2011 to 2017). With the evolution of the Malay-Muslim dressing norms during the specific time frame, various obstacles arose, but the HUSM continuously improved its nursing uniform in terms of practicality, professional image and Malay-Muslim features. The process of advocating for a Malay-Muslim friendly uniform in the post-colonial period was challenging, although Malay-Muslims account for the majority of the population and Islam is the official religion of Malaysia. HUSM has demonstrated practicality in blending
\end{abstract}


the local dressing norms within the professional dress codes while maintaining good standards of practice in healthcare.

Keywords: nursing uniform history, religious accommodation, cultural accommodation, Islamic healthcare dress code, Malay-Muslim women

\section{INTRODUCTION}

Nursing uniforms worldwide have undergone numerous changes since their appearance in the 19th century in Kaiserworth, Germany. That uniform consisted of a long-sleeved knee-length gown worn with an apron and a cap (that covers the hair except for the fringe) tied under the chin (Pearson et al. 2001). By the 20th century, nursing uniforms evolved to the commonly seen shorter skirts, shorter sleeves and smaller caps (Houweling 2004). The same design was also portrayed in a few post-independence Malay films, which depicted female nurse characters wearing white knee-length short-sleeved uniforms with nursing caps (Ramlee 1961). Currently, such uniforms are uncommon in Malaysia, as long trousers, long sleeves and headscarves predominate nursing uniforms in both public and private institutions. Although apparent transformations have been observed, there is no publication to date which has documented the evolution of nursing uniform in Malaysia and the experience of its advocates. This study seeks to document these issues by specifically presenting the case of the Hospital Universiti Sains Malaysia (HUSM), a teaching hospital under Universiti Sains Malaysia (USM).

\section{LITERATURE REVIEW}

When deliberating the event of a work attire policy change - in this case, the nursing uniform transformation - a number of issues arise. Since prior studies on accommodation for religious dressing in nursing are scarce, the literature on religious dressing accommodation in other sectors will be included. Hence, this literature review will include the evolution of work attire, the accommodation of religious dress at work, the non-religious factors driving changes in work attire policies, the religious factors that influence the change of policy, the process of the transformation, and the effects of non-religious and religious changes of work attire policies. 


\section{Transformation of Nursing Uniform}

In addition to the first nursing uniform recorded in Germany as described above, early nursing uniforms elsewhere have also been documented. For example, the nurses led by Florence Nightingale during the Crimean War in Europe wore grey long-sleeved long dresses with matching wool jackets, capes and brown scarves (Houweling 2004). Although there was no official nursing uniform during the American Civil War, the Union Army nurses led by Dorothea Dix were encouraged to wear brown, black or grey gowns with white aprons and bonnets. The Bellevue Hospital Training School was known to introduce the first official nursing uniform in America. This consisted of a calico dress with apron and detachable cuffs for easy hygiene maintenance. The early nursing uniforms in Australia closely resembled those of the American (Pearson et al. 2001). Over the decades, nursing uniforms have metamorphosed globally to numerous forms including short-sleeved trouser suits, knee-length dresses and scrub suits. Nurses' headgear has also changed to include a variety of forms including bonnets, veils and caps and has also been abandoned by many institutions (Houweling 2004). There is a lack of prior study on the evolution of nursing uniforms in Malaysia.

\section{Accommodation for Islamic Dressing at Work}

Headscarf-wearing at work has been an issue in many institutions in Muslimminority countries. In the United States of America, although anti-discrimination laws mandate that religious dressing be accommodated in the absence of any undue burden to the institution, only $17 \%$ of the 372 organisations surveyed by The Society for Human Resource Management accommodate religious dressing (Society for Human Resource Management 2008). In Canada, 40.6\% of survey respondents $(n=50)$ reported that they were asked not to wear headscarves at work (Persad and Lukas 2002). In the Netherlands, about 10\% of the complaints filed at the Anti-Discrimination Bureau in 2007 are headscarf-related (Choudhury and McCarthy 2010). It has been reported that headscarf bans at the workplace have occurred in institutions in Belgium and Germany (Choudhury and McCarthy 2010).

The situation in some Muslim-majority countries does not differ much from their Muslim-minority counterparts. Headscarf bans were imposed in the public sector in Turkey and Tunisia since the 1980s but had been lifted in the second decade of the 21st century (Tok 2009; Perkins 2012; Akoglu 2015). In Muslim-majority countries where headscarves are widely worn, occurrences of discrimination on the basis of headscarf-wearing have been reported. Amongst others, cases of nurses being denied the wearing of headscarves made newspaper headlines in Malaysia and Indonesia (Detik News 2011; Utusan Online 2013). In 
addition, headscarf bans have been widely imposed in many hospitality-based service providers in Malaysia (Nor Hafizan 2015).

To summarise, headscarf-wearing has been an issue for working women regardless of the religion of the majority in the country, including in Malaysia. Despite that, there has not been a prior study on the accommodation of Islamic dressing in the nursing workforce from a historical perspective in Malaysia.

\section{Factors, Challenges and Process of the Change of Dress Code}

\section{Non-religious factors, challenges and process of nursing uniform transformation}

Numerous factors have been responsible for the evolution of nursing uniforms as reported in the literature. Identity and image are common rationales behind the evolution to distinguish nurses, portray a professional image and follow up-to-date fashion trends. When Theodor Fliedner (who introduced the first nursing uniform in Germany) saw the challenge of incompliance to the uniform, he emphasised the importance of uniformity and iterated the need to prevent thriftiness, carelessness and complacency that may lead to infringement of the dress code. On the other hand, Nightingale - who encountered the challenge of making their uniform fashionably unique during the war - resorted to using scarves carrying the name of Scutari Hospital (Stimson 1936; Houweling 2004).

Practicality is another important factor in the design process, as nursing uniforms are required to facilitate work, infection control and maintenance. Nightingale nurses wore aprons as part of their uniform to promote cleanliness. Institutions in the United States of America resorted to detachable cuffs (since the late 19th century), white uniforms (since the 1900s) and abandonment of the cap (starting in the 1960s) to address the challenges of hygiene and infection control. When faced with financial constraints in the 1970s, institutions in the United States of America stopped supplying and laundering uniforms and transferred the responsibilities to their employees. Technological advancement had an effect on the uniforms, such as the invention of suitable materials including wrinkle-free fabrics (Stimson 1936; Houweling 2004).

The nurses' well-being has also been a driving factor in the uniform evolution as their human right, comfort, safety, health and modesty matter. For example, the difficulty of walking in kimonos led to the change in the Japanese nursing uniform in the 20th century (Takahashi 2004). In terms of human rights, American hospitals started lifting the trousers ban for female nurses in the 1970s in order to cope with anti-discrimination laws. Harmonising between the individual nurses' preference and the need for uniformity proved to be a challenge which was difficult to solve, until the use of multi-coloured scrub in the United States 
of America in the 1980s. Scrubs made individual expression possible while still having a uniform style (Stimson 1936; Houweling 2004).

Local norms are another factor in determining the uniform policy in the Eastern world. For example, the Japanese wore slimmer-sleeved kimonos as their uniform in the early 20th century (Takahashi 2004), while Indian nurses in some institutions have worn sarees at least since the 1940s (Jane 2017; The National Archives n.d.).

The history of nursing uniform evolution demonstrates various factors that need to be considered in the nursing uniform design sometimes contradict each other and require prioritisation. For example, institutions had to abolish the nursing cap which has been a traditional symbol for nurses to conform to infection control standards. There has been a lack of discussion on the process of uniform transformation, as most literature has focused on the uniforms themselves.

\section{Religious-related factors, challenges and process of the change of dress code in nursing and other sectors}

The increasing demand for religious dressing accommodation is believed to be influenced by increasing religiosity as a coping mechanism for personal, social and economic challenges. The phenomenon of increasing religious identity expression at work in the United States of America may be attributable to the dynamic of demography (increasing religiosity with age), economy, education (awareness of human rights) and technology (dehumanising and diminishing work-life boundaries). From the legal perspective, the enactment of anti-discrimination and religious rights laws also play a role in the phenomenon (Ball and Haque 2003; Kelly 2008).

Pressure from employees and Muslim associations may influence the change of work attire policy in an institution. Examples include cases of healthcare personnel resigning following the "bare below the elbows" policy introduced in the United Kingdom (BBC News 2008) in tandem with the advocacy by Muslim associations. The discussion between the Muslim Spiritual Care Provision, the Department of Health in the United Kingdom and local Muslim scholars led to the change of the "bare below the elbows" dress code to allow female Muslim personnel to cover their forearm with oversleeves, which allow compliance of both the infection control standard and Islamic dressing requirement (Department of Health United Kingdom 2010).

Robinson (2016) studied the challenges in advocating for headscarfwearing in the United States of America. The first issue is related to the Muslims community because there is disunity among Muslims and there are variances in opinions regarding the obligation to wear headscarves. Headscarves are also associated with the image of unprofessionalism and women enslavement by 
men (Robinson 2016). Employers perceive that customers have non-preference when dealing with employees wearing headscarves (Robinson, Franklin and Hamilton 2010). At the same time, disagreements regarding the responsibility to accommodate religious dressing, Islamophobia, stigmas and stereotypes concerning Muslims, and negative labelling of online collective actions (such as Saudi-linked, terrorist-links and extremist-linked) have further complicated the process (Robinson 2016). Robinson divided the approaches to online collective actions into two. The first is the instrumental approach, which involves the spread of information to improve Islamic awareness through various campaigns. The second is the symbolic approach, which involves identity formation pertaining to headscarves, such as the organisation of the Pink Headscarf Day and Headscarf Challenge to increase solidarity and inflict empathy of non-Muslims to experience headscarf-wearing. Additionally, there are non-governmental organisations that support Muslims by mediating disputes related to Muslim affairs including court cases. Robinson observed that boycotts had never been organised by Muslims towards institutions that ban the headscarf, unlike the "Boycott Zionism" campaign (Robinson 2016). Where headscarves are banned at the national level, lifting the ban requires amendments of the law, such as in Turkey (Tok 2009).

The above discussion depicts the challenges related to Islamic dressing accommodation, which can be classified into the standings of Muslims, the standing of the headscarf, and the perceived consequences of headscarf-wearing at work for the institution, its employees and its customers. The strategies - directed either to the working Muslim women or the policymakers - can be classified into explanatory (to improve awareness, knowledge and attitude); supportive (for example, legal support for court cases); negotiation (for example, negotiating for the alternative of using oversleeves); empathy appeal (for example, the Headscarf Challenge to experience the day as a headscarf wearer); and power reinforcement (for example, political power).

\section{Effects of the Transformation Dress Code}

\section{Effect of the non-religious-related changes of the nursing uniform}

Changing nursing uniforms have many effects on nursing, nurses and institutions themselves. The nursing uniform in one institution may inspire other institution. For example, the introduction of the uniform at the Deaconesses' Institute in German is believed to have influenced Nightingale to introduce uniforms for her nurses, which later is believed to have inspired the unofficial uniform during the American Civil War (Houweling 2004). After Nightingale introduced her uniform, nursing gained a new image in the eyes of the masses, including a respected secular image during the anti-papist era and a professional outlook (compared to untrained carers) with 
its own authority and pride. Despite that, the uniformity evoked dissatisfaction as the uniform design did not suit everyone, while the practicality of the ensemble (the bonnets, aprons and long dresses) was questioned. In the United States of America, the uniform indirectly motivated nurses to maintain a good demeanour to prevent nurses who donned the uniform from behaving inappropriately while in uniform to maintain the good image of their institution. Different reactions towards the uniform were observed among nurses with different socioeconomic backgrounds, as those from middle-to-upper-class perceived it as a form of enslavement, while the other group favoured it as a social liberation. Donning the uniform provided wearers with a sense of security while working with the public. The white uniform evolution in the United States of America in the 1940s led to mixed responses, as it improved the public perception of the hygiene standard but further lowered the image of nursing as being oppressed. When wrinkle-free fabrics were utilised, improvements in appearance and maintenance were observed. The oppressive image of the nursing uniforms was further amplified when higher-ranked nurses started wearing coats, business suits and scrubs in the 1970s. The currently popular scrub suits are favoured due to the beneficial effects on reducing cost, simplifying maintenance and unifying the image for healthcare personnel of all sexes, although the identity of nurses is said to have been increasingly lost as they become more indistinguishable from other healthcare personnel (Houweling 2004).

\section{Effect of the religious-related changes of the dress code}

Both beneficial and adverse effects have been observed when employees' religious needs are accommodated at the workplace. Religious accommodation is associated with loyalty and job satisfaction while perceived religious discrimination negatively affects their morale and productivity (Messarra 2014; Tanenbaum Center for Interreligious Understanding 2013). At the same time, religious accommodations may result in the perception of double standards among employees of different faiths when the accommodation affects the work environment. This may potentially lead to dissatisfaction and demotivation (among employees who viewed it as a double standard), leading to reduced output (Flake 2015).

\section{METHODS}

The qualitative approach is most appropriate to achieve the objectives of this study, as it allows the examination of experiences and processes (Creswell 2014, 32) in reforming the uniform in an institution. For this historical case study, the principal source of information for this study would be the working papers, meeting minutes, guidelines and circulars on the nursing uniforms. Unfortunately, it was impossible 
to retrieve these documents due to the unavailability of old documents and the confidentiality of extant documents. However, photos published on the official website of the HUSM Nursing Department and a blog by a medical technician at the HUSM Radiology Department provided valuable information regarding the uniforms used since 1983. Additionally, face-to-face unstructured interviews involving purposive sampling and snowball sampling of the key informants were conducted and audio was recorded. These two sampling methods were chosen because the main aim of this study was not to generalise the findings, but to obtain in-depth information regarding the case which involved a group of people who took part in the uniform reformation (Yin 2011, 88). The inclusion and exclusion criteria of the study participants for the interviews were as follows:

1. Inclusion criteria

i. The participant must be involved in or witness the nursing uniform transformation process at any period of time from the establishment of the institution to August 2017 (when the data collection took place).

ii. The participant must be able to converse in Malay or English.

2. Exclusion criteria

i. Participants with poor memory or intellectual disability.

ii. Participants with any debilitating illness.

The interviews were conducted by the first author (principal investigator, PI) as part of her doctoral research. The researchers and the participants had no relationship prior to study commencement. Both researchers are not from the state in which the institution is located and have never worked in the institution. The PI first approached the participants either in person (for participants who are still working at the institution), through e-mail or by telephone. The participants were informed regarding the objectives, rationale and method of the study. There was no refusal to participate or drop out. If they agreed to participate, consent for the interviews were obtained and the interviews were carried out at either their workplaces or their homes. The audio records of the interviews were transcribed verbatim within 24 hours after the interview was conducted. The transcripts were returned to the participants for the opportunity to correct the information that they provided, or to delete any information that they wished to be kept confidential. Content analysis was conducted based on the data collected which was done solely by the principal investigator. The Human Research Ethics Committee of USM provided ethical clearance for the study (USM/JEPeM/17020134). 


\section{RESULTS}

\section{Participant Information}

Ten individuals were identified as potential participants through purposive and snowball sampling. There were a small number of participants because the number of people who were involved in the process was small. Four of them could not be contacted because they had retired and the PI could not trace them. Six participants who met the criteria and were still working or have retired from working in HUSM since the 1980s were interviewed. All six participants were directly involved during the different phases of the process and provided adequate information to gain insight into the process within the timeframe of the study. Interview sessions lasted between 20 and 60 minutes. HUSM is relatively a small institution during its early years and the six participants are widely known by the HUSM members of staff due to their positions and their advocacy for the transformation process. Publishing the participants' demographic information (including age, position and duration served) would easily enable identification even without publishing their names. Since the participant demographics do not affect the analysis of the findings, the information will not be published to maintain the confidentiality of the participants.

\section{The HUSM Experience in Malaysianising the Nursing Uniform}

When the HUSM started operating in 1983, the nurses were on secondment from the Ministry of Health (MOH) (Unit Kejururawatan Hospital Universiti Sains Malaysia 2013) and continued wearing the MOH uniform, as shown in Table 1 (no. 1), until HUSM introduced its own uniform in 1984. The uniform resembled that of the MOH, with a slight difference in the design of the collar. The HUSM's uniform had a mandarin collar as shown in Table 1 (no. 2) which provided better coverage of the chest and neck, especially during the bending position. Nurses could opt for either the midi uniform or the trouser suit uniform. At the same time, negotiations for the Malay-Muslim-friendly uniform took place. Based on the narrative recollections of the participants, the factor that led to the negotiation for the Malay-Muslim-friendly uniform was the high level of Islamic awareness among the advocates, who included nurses and hospital administrators. For one of the nurse advocates, her mother's wish to not see her daughter wearing the short-sleeved midi-length uniform became her motivation to advocate for the Malay-Muslim-friendly uniform. She also realised the importance of nursing and wanted people from all walks of life to have the chance to take up nursing if it interested them without being deterred by the dress code (Participant 3). Another nurse advocate pointed out that the widespread Islamic education activities in 
Kelantan led to higher Islamic awareness. In addition, many Muslim nurses were also concerned that they would not be able to repent before dying as Participant 5 said:

Maybe because of this area, this state. We always hear from those who teach Islam tells about this...covering awrah. We have to think that our work is for life, we could say that because there are those who do not live long, who die before their retirement age. Might as well we do what we are supposed to do... So, that was what they did. So, we have to support (the efforts to advocate for the Malay-Muslim-friendly uniform).

In negotiating for a Malay-Muslim-friendly uniform, various challenges were experienced. For example, the Malay-Muslim-friendly uniform proposal was opposed by several HUSM senior nurses and USM top administrators, while the HUSM administrators were in favour of the proposal. The nurses who opposed the proposed Malay-Muslim-friendly uniform were those who received training in the West and who were proud of the uniform tradition (Participants 3 and 5). There were many reasons provided for opposing the uniform. Firstly, the existing uniform was seen as a pretty ensemble (Participant 3). Secondly, the uniform had been a long-standing nurse tradition and identity (Participants 3 and 6). Thirdly, long sleeves and headscarves were considered potential hazards for contamination and nosocomial infection transmission (Participant 3). Fourthly, individuals who opposed the proposal asserted that it was considered darurah (out of necessity) for nurses to wear the midi uniform to work by comparing the situation with footballers' uniforms (Participant 6). In order to cope with the resistance, the advocates responded in a number of ways. Regarding the issue of keeping the traditional identity of nurses, the advocates used a different approach by questioning the prioritisation of functional features verses decorative features of the uniform and highlighted that historically, the cap started as a headgear intended to cover the whole hair (Participant 6). To deal with the concerns towards the potential breach of infection control practices, two approaches were considered.

First, in debating the issue, the use of the nursing cap and surgical cap were compared with the headscarf.

I said to them, "How many of you wash your caps every week?" Maybe not even once a month. I didn't wash my cap every week, sometimes not even every month. I just put it; I don't know what was present there. If you wear headscarves, you will feel uncomfortable wearing the same headscarf for two days. If you wear one headscarf today, tomorrow you need to change it to a new or washed headscarf. In terms of hygiene, why don't you take the cap and check (the bacterial count)? And then try taking the headscarf that I wore yesterday or any day that you want to take and check it in the lab, you can take it. "What if I want to take your 
cap today and I want to check it in the labs, how do you feel?" (They said), "Can you take it tomorrow? I want to wash it first". It was not easy to clean the cap, we have to starch it in order to make it neat and shiny, it was not easy... I told them, "If we are in the operation theatre (OT), we cover everything except our eyes, so why can't we (cover) outside the OT when the principle is the same?" (Participant 3)

Second, the advocates conducted a scientific study to compare the contamination among nurses wearing nurse caps and headscarves. The study showed that the contamination was lesser among nurses who wore headscarves, likely because there was no hair fall. Unfortunately, the study was not published (Participant 6). In addition, to conform to the good clinical practice standards, the sleeves of the Malay-Muslim-friendly uniform were designed to be easily rolled to facilitate hand washing during clinical care (Participants 1, 3, 4 and 5) and easily unrolled once the procedure has been completed.

Since the proposal for the Malay-Muslim-friendly uniform was not approved by the USM top administrators despite the negotiation efforts, the HUSM Director, Datuk Dr. Kamaruzaman Wan Su, permitted a "trial-run" Malay-Muslim-friendly uniform to provide semi-official permission for selected nurses to wear the uniform without breaking the official uniform policy as it was only declared as a trial-run (Participants 3, 5 and 6). The uniform consisted of long-sleeved tunics with trousers and headscarves, as shown in Table 1 (no. 3) (A Medical Technician at the Radiology Department Blog 2013). The uniform was only permitted for selected nurses who proved to perform well in their service and had good demeanours, with the support of their head nurses (Participants 3, 5 and 6). The rationale for this was twofold. Firstly, it was intended to ensure that the uniform was not blamed for any unwanted incidents such as hospital-acquired infections. Secondly, it served as a reward which would motivate nurses who wanted to wear the Malay-Muslim-friendly uniform to improve their performance and demeanour. Nurses who wished to wear the trial-run uniform had to write an application letter and obtain the support of their head nurses (Participants 3, 5 and 6). The trial-run uniform included a knee-length tunic with trousers to ensure adequate coverage of awrah (body parts required to be covered in Islam) in all ranges of movements. A headscarf worn over the top attire which extends below the chest completed the ensemble. There was a suggestion to have nurses who wear the trial-run uniforms to tuck-in their headscarves inside the top attire to facilitate nursing works. However, the suggestion was not supported by the advocates, as they opined that tucking-in the headscarves would enhance the shape of the bust; hence, the suggestion was not materialised as Participant 3 shared her views:

The headscarves were worn over the top attire and have never been tucked in because if it is tucked in, the chest will be bulging, so I told 
them that it should not be tucked in because it will accentuate the shape of the chest. Are we supposed to show off our chests or cover it?

After the introduction of the Malay-Muslim-friendly trial-run uniform, nurses who were interested in wearing the uniform consulted the advocates among the senior nurses. In order to help them gain permission, one of the nurse advocates helped junior nurses write the letters of application and guided them through the procedure. At that time when digital technology was still scarce, it was a challenge to retype a new letter every time when it was needed as Participant 3 stated, "Everyone who wished to wear the Malay-Muslim-friendly (trial-run) uniform had to submit an application letter. At that time, we only had typewriters, it was considered advanced... So, I helped with the letters".

After having the trial-run uniform for a few years, the USM top administrators ordered the cessation of the trial. To convince the top administration, an analogy was used to induce empathy as Participant 6 expressed, "How would you feel if you are being told to wear shorts to work?". At the same time, the nurses kept praying that the trial-run uniform would not be revoked so that they would not need to turn back to the short-sleeved uniform without headscarves.

When we meet those who wear the (trial-run) uniform, I always remind them, "Please make prayers, we will be having a meeting tomorrow about the uniform, pray that it will be easy, pray that the uniform will be officiated, what would happen if tomorrow the top administration tells us to stop wearing this (trial-run) uniform?" (Participant 3)

The trial-run uniform persisted and allowed the selected nurses to cover themselves according to Islam, but the exact number of nurses who were given the permission is unknown. Interestingly, the nurses who initially opposed the Malay-Muslimfriendly uniform later adopted the uniform to become among the selected nurses allowed to wear it (Participant 5). Hence, the trial-run uniform became a form of $d a^{c}$ wah (call to Islam) which increased the awareness among HUSM personnel. From another perspective, the change in nursing uniform also put HUSM under a different spotlight. The long sleeves, headscarves and knee-length tunics were questioned by other healthcare institutions as posing a hindrance towards good nursing practice, despite the absence of observable adverse effect of the uniform, such as in terms of the infection rates (Participant 5). 
Table 1: Nursing uniform evolution at HUSM

\begin{tabular}{|c|c|c|c|}
\hline No. & Uniform & Details & Illustration \\
\hline 1. & & $\begin{array}{l}\text { Period: } 1983-1984 . \\
\text { Nurses could choose to either } \\
\text { wear the midi gown or the blouse } \\
\text { with pants. } \\
\text { Different ranks of nurses were } \\
\text { distinguished through the } \\
\text { different colours of the lines on } \\
\text { the cap: } \\
\text { - Assistant nurse: white uniform, } \\
\text { a red line on the cap. } \\
\text { - Midwife: white uniform, a } \\
\text { green line on the cap. } \\
\text { - Staff nurse: white uniform, a } \\
\text { blue line on the cap. } \\
\text { - Sister: white uniform, no line } \\
\text { on the cap. } \\
\text { - There was no Matron in } 1983 \text {. }\end{array}$ & $\begin{array}{l}\text { Illustration by the } \\
\text { author based on } \\
\text { the information } \\
\text { obtained from } \\
\text { Medical Technician } \\
\text { at the Radiology } \\
\text { Department Blog } \\
\text { (2013). }\end{array}$ \\
\hline 2. & & $\begin{array}{l}\text { Period: } 1984-\text { the mid- } 1990 \mathrm{~s} \text {. } \\
\text { Nurses could choose to either } \\
\text { wear the midi gown or the blouse } \\
\text { with pants. } \\
\text { Different ranks of nurses were } \\
\text { distinguished through the } \\
\text { different colours of the uniform } \\
\text { and the lines on the cap: } \\
\text { - Assistant nurse: white uniform, } \\
\text { two red lines on the cap. } \\
\text { - Midwife: white uniform, two } \\
\text { green lines on the cap. } \\
\text { - Staff nurse: white uniform, two } \\
\text { purple lines on the cap. } \\
\text { - Sister: blue uniform, no line on } \\
\text { the cap. } \\
\text { Matron: pink uniform which } \\
\text { was later changed to nude- } \\
\text { colour uniform in the end of } \\
\text { the 1980s (the exact date could } \\
\text { not be determined), no line on } \\
\text { the cap. }\end{array}$ & $\begin{array}{l}\text { Illustration by the } \\
\text { author based on } \\
\text { the information } \\
\text { obtained from } \\
\text { Participants } 1 \text { and } \\
5 \text {, and Medical } \\
\text { Technician at } \\
\text { the Radiology } \\
\text { Department Blog } \\
\text { (2013). }\end{array}$ \\
\hline
\end{tabular}


Table 1: (continued)

\begin{tabular}{|c|c|c|c|}
\hline No. & Uniform & Details & Illustration \\
\hline 3. & & $\begin{array}{l}\text { Period: } 1986 \text {-the mid-1990s. } \\
\text { The trial-run uniform for selected } \\
\text { nurses while other nurses } \\
\text { continued to wear the uniforms } \\
\text { as shown in (2), with or without a } \\
\text { black hair cover. } \\
\text { Different ranks of nurses were } \\
\text { distinguished through the } \\
\text { different colours of the uniform } \\
\text { and the lines on the edge of the } \\
\text { headscarf: } \\
\text { - Assistant nurse: white uniform, } \\
\text { two red lines along the edge of } \\
\text { the headscarf. } \\
\text { - Midwife: white uniform, two } \\
\text { green lines along the edge of } \\
\text { the headscarf. } \\
\text { - Staff nurse: white uniform, two } \\
\text { purple lines along the edge of } \\
\text { the headscarf. } \\
\text { - Sister: blue uniform, no } \\
\text { line along the edge of the } \\
\text { headscarf. } \\
\text { - Matron: pink uniform which } \\
\text { was later changed to nude- } \\
\text { colour uniform in the end } \\
\text { of the 1980s (the exact date } \\
\text { could not be determined), } \\
\text { no line along the edge of the } \\
\text { headscarf. }\end{array}$ & $\begin{array}{l}\text { Illustration by the } \\
\text { author based on } \\
\text { the information } \\
\text { from Participants } \\
1,3,4,5 \text { and } 6 \text {, and } \\
\text { Medical Technician } \\
\text { at the Radiology } \\
\text { Department Blog } \\
\text { (2013). }\end{array}$ \\
\hline
\end{tabular}


Table 1: (continued)

\begin{tabular}{lll}
\hline Illustration \\
\hline 4.
\end{tabular}


Table 1: (continued)

\begin{tabular}{|c|c|c|c|}
\hline No. & Uniform & Details & Illustration \\
\hline 6. & $\checkmark$ & $\begin{array}{l}\text { Period: } 2014-\text { present. } \\
\text { The uniform for (a) U42/44 } \\
\text { Matrons and the Chief Matron; } \\
\text { and (b) for other nurses. } \\
\text { Different ranks of nurses are } \\
\text { distinguished through the } \\
\text { different bias lines on the } \\
\text { princess line. } \\
\text { - Assistant nurse, midwife and } \\
\text { community nurse: purple } \\
\text { uniform with no bias line on } \\
\text { the princess line and light } \\
\text { purple headscarf. } \\
\text { - Staff nurse: purple uniform } \\
\text { with a light purple bias line } \\
\text { on each princess line and light } \\
\text { purple headscarf. } \\
\text { - Sister: purple uniform with } \\
\text { a green bias line on each } \\
\text { princess line and light purple } \\
\text { headscarf. } \\
\text { - Matron: purple uniform with a } \\
\text { red bias line on each princess } \\
\text { line and light purple headscarf. } \\
\text { - U42/44 Matrons and the Chief } \\
\text { Matron: maroon uniform with } \\
\text { pink headscarf. }\end{array}$ & $\begin{array}{l}\text { Illustration by the } \\
\text { author based on } \\
\text { the information } \\
\text { obtained from Unit } \\
\text { Kejururawatan } \\
\text { Hospital Universiti } \\
\text { Sains Malaysia } \\
\text { (2016). }\end{array}$ \\
\hline
\end{tabular}

The trial-run uniform was finally officiated with the introduction of new nursing uniforms in the mid-1990s, but the exact year could not be determined. The design of the uniform still maintained the design of the previous trial-run uniform. The uniform also featured a unique identity for the HUSM nurses with the use of nontraditional colours to distinguish the different ranks of nurses, as shown in Table 1 (no. 4). Nurse supervisors (matrons) who were not involved in direct patient care wore an ankle-length straight skirt instead of trousers. The Islamic dressing rules have no preference of skirt over pants, as long as the pants are loose (Abdul Karim 1993). This suggests that there was an accommodation towards the local culture, as the nurse supervisors wore long skirts which closely resembled the bottom pieces of the traditional Malay dresses (baju kurung and baju kebaya), known as sarong. The challenges related to the opposition of the Malay-Muslim-friendly 
uniform ceased but they faced a new challenge related to the issue of the supply of the material. As the uniform involved various colours, ensuring that every batch of supply matches the intended colour proved to be a challenge (Participant 1). As a result of the officiation, one of the participants recalled that the then Chief Minister of Kelantan, Dato' Bentara Setia Nik Abdul Aziz Nik Mat, praised the uniform in the local newspaper and urged other uniform bodies to allow their female personnel to wear similar Malay-Muslim-friendly uniforms (Participant 3). Besides the positive feedback from the local population, the HUSM started receiving various visits from other institutions who were interested in introducing similar uniforms in Malaysia and abroad (Participant 3).

In 2011, the uniform underwent another transformation, which was mainly motivated by professional reasons to portray a unified corporate image under the 1-USM idea. Since the corporate colour of the USM is purple, thus the colour of the uniform was changed to purple for all ranks of nursing staff (Participant 1) but maintained the long-sleeved tunic trouser suit form, as shown in Table 1 (no. 5). The uniforms include lycra headscarves with hard visors, in line with the local fashion innovation, making the wearer look smart and neat with the wrinkle-free lycra fabric. Different designs of the wrist cuff differentiate the different ranks of the nursing personnel (Unit Kejururawatan Hospital Universiti Sains Malaysia 2016). However, the mode of differentiating the various ranks of nursing personnel through the different design of the wrist cuffs was problematic, because the cuffs became hidden when the sleeves were rolled for hand hygiene purpose during direct patient care (Participant 1). Thus, the uniform was transformed to a new version in 2013 (Unit Kejururawatan Hospital Universiti Sains Malaysia 2016), as shown in Table 1 (no. 6), which allowed for easier discernment of the different ranks of nurses (even during tasks requiring the sleeves to be rolled) while still maintaining a unified corporate image. To achieve the criteria of the desired uniform, HUSM sought a professional opinion to help design the uniform. An expert in fashion designer from Universiti Teknologi MARA (UiTM) was involved in the process of developing the latest uniform. The designer suggested the use of multicoloured bias line on the princess cut line which is visible during all situations (Participant 1). However, the uniform is seen as non-sharia-compliant by a group of the society (Participant 5), as the princess cut gives the illusion of the women's figures, which Islam obligates covering. This version of the uniform continues to date. 


\section{DISCUSSION}

\section{Phases of Nursing Uniform Development at the HUSM}

Based on the findings, the HUSM uniform journey can be divided into three phases. The first phase during the first decade of its establishment illustrates the process of the establishment of a distinct HUSM identity and negotiation for Malay-Muslimfriendly nursing uniforms. The challenges of negotiating for a Malay-Muslimfriendly uniform were most difficult at that time as HUSM introduced a new trial-run uniform different from the conventional standards, in tandem with the low Islamic awareness in Malaysia and widespread misconceptions regarding the Islamic dressing rules and the rules of darurah. These factors contributed to the rejection of the Malay-Muslim-friendly uniform, causing the HUSM to endure the negative consequences. The perceptions of the individuals who opposed the MalayMuslim-friendly uniform suggest their strong affiliation with colonial heritage and conventional nursing standards to such an extent that they were unwilling to compromise them to accommodate the religious needs although alternative methods could be used to comply with the standards while accommodating Islamic dressing rules. On the other hand, the uniform satisfied nurses with a strong Islamic background who were previously saddened by the denial of their right to practice their religion at the workplace. The advocates of the uniform showed a high level of wisdom and creativity in handling the difficult situation. Debating on the issue based on non-religious bases (such as by arguing the hygiene status of the cap and by conducting experiments comparing the contamination by nurses with and without headscarves) was apt, as the opposing party may had unfavourable attitudes towards the Islamic practices but valued scientific justifications. Introducing the uniform on grounds of trial-run allowed HUSM nurses to wear the Malay-Muslim-friendly uniform without overtly breaking the rules. In addition, the trial-run uniform, which operated as a reward system, was like killing two birds with one stone, as making it a reward system. Not only did the nurses who were allowed to wear the new uniform feel appreciated, but it also ensured that nurses who wore it really portrayed professionalism, which is a positive feedback mechanism to justify the benefits of the new uniform. While advocating for the cause, the advocates also demonstrated spiritual efforts to cope with the challenges facing them by increasing their prayers.

The second phase in the next decade involved officiation of the MalayMuslim-friendly nursing uniform as a distinct identity for the HUSM as the uniform became compulsory for all Muslim nurses. An element of the Malay cultural dressing was injected through the use of the ankle-length skirt suits for senior nurses. Unlike the previous phase, none of the participants recalled any challenges during this phase. This is likely due to the improved Islamic awareness 
of the masses compared to the previous phase, resulting in high acceptance by the members of staff, the public and other institutions interested in introducing MalayMuslim-friendly uniform in Malaysia and abroad.

The current phase (since 2011) reflects efforts towards highlighting the corporate image of the HUSM while continuously improving the practicality of the uniform. This is evident in the standardisation of the uniform colour with the USM corporate colour, the introduction of the headscarves with hard visors and the use of coloured bias line to improve discernment of nursing ranks. The increased professionalism of HUSM may be observed in that the input of a professional designer was involved to overcome the challenge of designing a uniform that fulfilled all the objectives of the uniform, including fulfilling local dressing needs, facilitating good nursing practices and showcasing HUSM's distinct corporate image. The uniform generally does not contradict the local Malay-Muslim dressing norm and thus, is well accepted despite the issue of the inability of the uniform to fully obscure the figure of the wearer.

In summary, the HUSM has faced several challenges and experienced different responses during each phase, depending on the Malay-Muslim dressing norms during the specific time frame. In the process of the uniform transformation, the advocates were resourceful and implemented diverse strategies to overcome the challenges. In light of HUSM's uniform journey, it is likely that HUSM would continue to improve its uniforms in future.

\section{Similarities and Differences with Nursing Uniforms Evolutions in Other Institutions}

The HUSM nursing uniform transformations share some similarities and also differences with uniform evolution in other institutions reported in past literary works. The HUSM uniform started with the midi-skirt version and evolved to the ankle-length skirt and trousers version while the uniform evolution reported in the literature started with the ankle-length skirts, followed by shorter skirts and later, the use of trousers. Trousers were introduced in American hospitals in the 1970s, while HUSM began using them in 1986 when the trial-run period started. Long sleeves were first used in nursing globally and were later replaced with short sleeves, but the case of the HUSM is to the contrary. Similarly, the case of HUSM is contrary to other institutions globally, as initially other institutions used headgears that fully covered the hair and later evolved to become smaller caps. The earliest form of nursing uniform carried some form of religious image, as nursing work was performed by deaconesses, but later evolved to carry a secular image, while the HUSM nursing uniforms are the opposite of that as they started with a secular image which was reformed to become more Malay-Muslim friendly. The lifting of headscarf bans similar to HUSM's ban also occurred recently in other 
Muslim countries such as Turkey and Tunisia. Currently, HUSM is still using specific uniforms for nurses, unlike many institutions in other countries that have abandoned such uniform for scrubs.

In terms of uplifting identity, the influence of fashion can be seen in the case of HUSM (the use of instant headscarves with hard visors) and other institutions discussed in the literature review section above. The strategy of using the name the institution on the uniform to enhance corporate image has never been used by the HUSM, unlike Nightingale's Scutari Hospital uniform. Hygiene and infection control remain the major consideration in the uniform design, but HUSM uses easily-rolled sleeves instead of detachable sleeves and cuffs (used in American hospitals in the 19th century). Anti-wrinkle fabric is used by HUSM (for the material of the nurse headscarves), as had been used in the American institutions. Anti-discrimination was not mentioned as a factor for the nursing uniform transformation in the HUSM but the analogy of "men wearing shorts as uniforms" was used by one of the HUSM advocates to justify the need to continue to allow nurses to wear the trial-run Malay-Muslim-friendly uniform. The HUSM shares similar policy related to the accommodation of local dressing norm (through the use of sarong - like skirt for senior HUSM nurses), which has been reported in Japanese and Indian healthcare institutions.

The increasing religiosity phenomenon and increasing demand to wear religious-conforming attire at work in Malaysia may also be observed in other countries, as discussed in the literature review. The problem of disagreement among Muslims regarding the obligation to wear headscarves was found in the present study, similar to what have been described by Robinson (2016). Islamophobia, stigmas and stereotypes concerning Muslims and the advocates did not surface in the present study, likely because the institution is situated in a Malay-Muslimmajority state, unlike the situation in other Muslim-minority countries. Advocating strategies through explanatory, supportive and empathy appeal has been used by the HUSM, similar to previous effort described by Robinson (2016).

Comparing the effects of the uniform transformation, there were variances in acceptance of the newly introduced uniforms, similar to what have been reported in past literary works. The image of enslavement by the use of the uniforms was not mentioned by any of the participants of the present study, unlike the situation in other countries discussed above. The inter-institutional effect of inspiring other institutions to introduced similar uniforms is comparable to the Kaiserworth Deaconesses' Institute's influence on Nightingale's nursing uniform, and Nightingale's influence on the unofficial American Civil War nursing uniform. The effect of the uniform in motivating nurses to maintain good demeanour is evident in HUSM's case, as well as the aforementioned institutions cited in the literature review. In HUSM's case, the negative effect of the uniform related to demotivation due to perceived double standard has never been reported. 


\section{Limitations}

In this study, the absence of primary materials and original records of the events is an unavoidable limitation. Copies of the original documents (such as working papers, proposals, circulars and application letters) related to nursing uniform changes have been lost or destroyed. The confidentiality of the materials is also another barrier to data collection. Some of the documents, although may still be available may be treated as confidential. Due to these two factors, a fraction of the information was obtained through interviews with the participants, which were dependent on their ability to recall the event. To address this limitation, the researchers tried to corroborate the information provided by different participants. Another limitation is related to the confidentiality of the participants where the researchers could not acknowledge their names and contribution; hence, they remain unsung heroes.

\section{Recommendations}

The process of accommodating local religio-cultural needs of various aspects of practice is an ongoing process in many institutions. Practically, the strategies used by the senior generation of HUSM could be an exemplary model for any similar effort. In introducing a new policy, advocates ought to be wise in justifying the need for the change, understanding the reasons for resistance, overcoming the challenges, introducing the new policy gradually and preventing (or minimising) problems associated with the new policy.

Although the study has attempted to reduce the gap in the literature in terms of the history of the Malaysianisation of the nursing uniform in HUSM, the findings have lead to new research questions. Firstly, the study was only conducted in HUSM, so it would be interesting to know the case of other institutions in Malaysia, other Muslim majority countries and Muslim-minority countries. The result would be beneficial to provide insight into the process of harmonising local religio-cultural needs within the professional sphere in Malaysia specifically and also globally. Further research would also allow the comparison of different cultures and the process of similar efforts between different institutions or countries.

\section{CONCLUSION}

The evolution of nursing uniform has seen tremendous changes in the last few decades, but little had been known regarding the story behind the evolution of nursing uniform in Malaysia, which involved great efforts of many people who advocated for the change. In Malaysia, the modern healthcare system and nursing 
were introduced by the British during its colonial rule in Malaysia. Although HUSM was established in the third decade after independence, the colonial influence in the Malaysian healthcare system was still prominent, including nursing uniforms. The case illustrates that despite being in a Muslim-majority country where the status of Islam is safeguarded by the constitution, it was challenging to advocate for the Malay-Muslim-friendly uniform during the time when the values of the Malay-Muslim professionals still carried the remnants of the colonial past, which led to resistance towards the Malaysianisation process.

The case of the HUSM nursing uniform depicts the possibility of fusing the local religio-cultural dressing needs within the professional sphere without undermining the standards of good service despite initial surmise of the potential threat towards infection control. Although one may argue that the current uniform may not be fully sharia-compliant, prominent changes have taken place with regard to nursing uniform design which have become more conforming to the Islamic dressing requirement. Undoubtedly, further improvement could be made but HUSM deserves to be acknowledged on their success so far.

\section{ACKNOWLEDGEMENTS}

We declare no conflict of interest. The present study received no financial assistance from any source. We thank the Director of the HUSM, Kubang Kerian, Kelantan and the HUSM Nursing Department for granting the permission to the investigators to collect data from the nursing staff and retrieve information from the official website of the HUSM Nursing Department and the blog of a medical technician at the HUSM Radiology Department. Special thanks go to the staff of the HUSM who tirelessly assisted us in making the research successful. We are also grateful to the Human Research Ethics Committee of USM (JEPeM) for providing the ethical clearance (USM/JEPeM/17020134).

\section{REFERENCES}

Abdul Karim Zaydan. 1993. Al-Mufașșal fì ahkām al-mar'ah wa al-bayt al-muslim $f i$ al-shari'ah al-islamiyyah [Encyclopaedia of rulings pertaining to women and Muslim families in Islamic sharı̄'ah]. Vol. 3. Beirut: Mu'assasat al-Risalah.

Akoglu, K.S. 2015. Piecemeal freedom: Why the headscarf ban remains in place in Turkey. Boston College International and Comparative Law Review 38(2): 277-304.

Ball, C. and A. Haque. 2003. Diversity in religious practice: Implications of public workplace. Public Personnel Management 32(3): 315-330. https://oi. org/10.1177/009102600303200301 
BBC News. 2008. Muslim quits over bare arm policy. 2 September. http://news.bbc.co.uk/ go/pr/fr/-/2/hi/uk_news/england/berkshire/7593827.stm (accessed 9 June 2018).

Choudhury, T. and M. McCarthy. 2010. Muslims in Europe: A report on 11 EU cities. New York: Open Society Institute.

Creswell, J.W. 2014. Research design: Qualitative, quantitative and mixed method approaches. California: Sage Publications Inc.

Department of Health United Kingdom. 2010. Uniforms and workwear: Guidance on uniform and workwear policies for NHS employers. Leeds, United Kingdom: Department of Health United Kingdom. https:/www.whatdotheyknow.com/ request/288156/response/702370/attach/3/uniform $\% 20$ revised $\% 20$ guidance $\% 20$ 2010.pdf (accessed 9 May 2020).

Detik News. 2011. Dilarang pakai jilbab, perawat laporkan RS Delta Surya Ke LBH. 25 January. https://news.detik.com/berita-jawa-timur/1554411/dilarang-pakaijilbab-perawat-laporkan-rs-delta-surya-ke-lbh (accessed 2 January 2018).

Flake, D.F. 2015. Bearing burdens: Religious accommodations that adversely affect coworker morale. Ohio State Law Journal 76(1): 169-216. https://doi.org/10.2139/ ssrn. 2474715

Houweling, L. 2004. Image, function and style: A history of the nursing uniform. American Journal of Nursing 104(4): 40-48. https://doi.org/10.1097/00000446-20040400000016

Jane, S. 2017. Proposal gets nod, Tamil Nadu nurses to get new attire. The New Indian Express. 30 May. https://www.newindianexpress.com/cities/chennai/2017/ may/30/proposal-gets-nod-tamil-nadu-nurses-to-get-new-attire-1610656.html (accessed 29 January 2018).

Kelly, E.P. 2008. Accommodating religious expression in the workplace. Employee Responsibilities and Rights Journal 20(1): 45-56. https://doi.org/10.1007/ s10672-007-9059-6.

Medical Technician at the Radiology Department Blog. 2013. Memorable photographs from the 1980s - At Radiology Department, HUSM. 17 April. http:/ juruteknikperubatan.blogspot.com/2013/04/memorable-photographs-from1980s-at.html (accessed 9 August 2017).

Messarra, L.C. 2014. Religious diversity at work: The perceptual effects of religious discrimination on employee engagement and commitment. Contemporary Management Research 10(1): 59-80. https://doi.org/10.7903/cmr.12018.

Nor Hafizan Habib Sultan. 2015. Stereotaip gender dan pekerjaan wanita dalam sektor perhotelan di Pulau Langkawi, Kedah. MA diss., Universiti Sains Malaysia.

Pearson, A., H. Baker, K. Walsh and M. Fitzgerald. 2001. Contemporary nurses' uniforms - History and traditions. Journal of Nursing Management 9(3): 147-152. https:// doi.org/10.1046/j.1365-2834.2001.00207.x.

Perkins, T. 2012. Unveiling Muslim women: The constitutionality of hijab restrictions in Turkey, Tunisia and Kosovo. Boston University International Law Journal 30(2): 529-565.

Persad, J.V. and S. Lukas. 2002. No hijab is permitted here: A study on the experiences of Muslim women wearing hijab applying for work in the manufacturing, sales and service sectors. Toronto: Women Working with Immigrant Women. 
Ramlee, P. 1961. Seniman bujang lapok. Singapore: Malay Film Productions.

Robinson, R.S. 2016. Hijab in the American workplace: Visibility and discrimination. Culture and Religion 17(3): 332-351. https://doi.org/10.1080/14755610.2016.1 211543.

Robinson, R.K., G. Mc-C. Franklin and R.H. Hamilton. 2010. The hijab and the kufi: Employer rights to convey their business image versus employee rights to religious expression. Southern Law Journal XXII: 79-88.

Society for Human Resource Management. 2008. Religion and corporate culture Accommodating religious diversity in the workplace. Alexandria: Society for Human Resource Management.

Stimson, J.C. 1936. The nurses uniform. The American Journal of Nursing 36(4): 367372. https://doi.org/10.2307/3412147

Takahashi, A. 2004. The development of the Japanese nursing profession. London: Routledge Curzon.

Tanenbaum Center for Interreligious Understanding. 2013. What American workers really think about religion: Tanenbaum's 2013 survey of American workers and religion. New York: Tanenbaum Center for Interreligious Understanding.

The National Archives. n.d. A case study - Women's Auxiliary Corps (India). http:// www.nationalarchives.gov.uk/womeninuniform/wwii_profile.htm (accessed 30 January 2018).

Tok, G.C. 2009. The securitization of the headscarf issue in Turkey: The good and bad daughters' of the republic. Ritsumeikan Annual Review of International Studies 8: 113-137.

Unit Kejururawatan Hospital Universiti Sains Malaysia. 2013. Profil. http://h.usm.my/ nursing/index.php/tentang-kami (accessed 9 August 2017).

. 2016. Galeri. http://h.usm.my/nursing/index.php/galeri (accessed 9 August 2017).

Utusan Online. 2013. Buka tudung jika mahu kerja. 18 June. http:/ww1.utusan.com. my/utusan/Forum/20130618/fo_01/Buka-tudung-jika-mahu-kerja (accessed 11 August 2018).

Yin, R.K. 2011. Qualitative research from start to finish. New York: The Guildford Press. 